\title{
Lithuanian activities in energy security
}

\author{
J. Augutis ${ }^{1,2}$, R. Krikštolaitis ${ }^{1,2}$ \& E. Ušpuras ${ }^{1}$ \\ ${ }^{1}$ Lithuanian Energy Institute, Lithuania \\ ${ }^{2}$ Vytautas Magnus University, Lithuania
}

\begin{abstract}
The energy security level assessment methodology and calculation results are presented in this paper. This paper is a result of an interdisciplinary work encompassing energy system modelling, analysis of technical, economic, environmental, sociopolitical and other threats and their consequences as well as the assessment of integral energy security level. The novelty and originality of this work is represented by the interdisciplinary integration of the developed methods: not only technical and economic information of the system, but also sociopolitical assessment of threats and sociological analysis of consequences are included into the assessment of the causes and consequences of the energy system disturbances. Test calculations were carried out according to this methodology and individual examples and scenarios were discussed. Some conclusions can already be drawn from these calculations. For instance, several basic groups of threats to the Lithuanian energy system may be distinguished, such as dependence on a single supplier of energy sources, great dependence on fuel and energy import, lack of energy network integration to the EU networks and energy markets, low energy use efficiency, domination of monopolies in the energy system, lack of energy infrastructure development and its vision. The shutdown of Ignalina NPP has had some negative (increase of electricity cost, gas and electricity import) as well as positive (a real electricity market was established, the dependence of Lithuania on a single power plant unit was eliminated, the development of renewable energy sources became more active) consequences for the Lithuanian energy security. The calculations demonstrated that the Lithuanian energy security level only very slightly declined after the shutdown of Ignalina NPP (approximately 6\%). New projects for the development of the Lithuanian energy, such as electricity connection to Sweden and Poland, liquefied gas terminal, a new nuclear power plant, etc., fundamentally increase the Lithuanian energy security level. Having performed
\end{abstract}


the work, it was determined that electricity connection to Sweden would increase the energy security level by about $4.5 \%$, liquefied natural gas terminal $-11 \%$ and Visaginas nuclear power plant $-12 \%$.

Keywords: energy security, energy system, strategic initiatives.

\section{Introduction}

Efficient functioning of energy sector is particularly important for every modern state economy - almost all economy fields are directly or indirectly related to production, import, export or transportation of energy sources. Sectors of industry, transport and agriculture particularly depend on the functioning of energy system. Economical and technical processes in energy sector may influence other state's functioning fields as well: to guarantee security (via energy sources supply for military objects and transport), social processes (via changes of consumer demands and expenses on fuel, heating and power), communication (due to direct dependence of communication systems on power supply), ecology (via energy impact on the environment) and politics (via enforcement power and consumer interest-groups on political institutions), thus energy security is an inherent part of state's economy security [1].

Currently in Europe and worldwide there are no globally accepted criteria and methods how quantitatively evaluate allowable energy supply strategic dependence on supply from a country, which due to different reasons may be treated as unreliable supplier or uses energy and other raw material supply for political purposes. Performed investigations in this field often are confidential and are not published in public scientific print media. Security of energy supply assessments submitted by now are based on criteria of individual scientists, very often are based on the review of probable supply alternatives or political motives. Development of common energy security assessment methodology is complicated by the fact that it must be interdisciplinary, integrating research of energy, economy, system reliability, risk, politology, sociology and other directions.

The Lithuanian situation of energy supply security is quite complicated in comparison to other European countries: few countries supply primary energy sources, there are no networks of gas, oil and electricity to Western Europe and the transmission grid needs modernization. Prior to 2010 Lithuania was a nuclear power energy producing country. More than $75 \%$ of the total Lithuanian electricity production consisted of nuclear power energy. Due to the accession of the Republic of Lithuania to the EU, Lithuania committed to shutdown the first Ignalina NPP block in 2004 and the second block in 2009 [2]. Therefore, since the beginning of 2010, both blocks of Ignalina NPP have been shut down and Lithuanian energy system became highly dependent on import of electricity and fossil fuels. Lithuanian dependency on primary energy sources is presented in fig. 1. The comparison of appropriate primary energy sources between Lithuania and EU-27 in 2009 is presented in fig. 2 


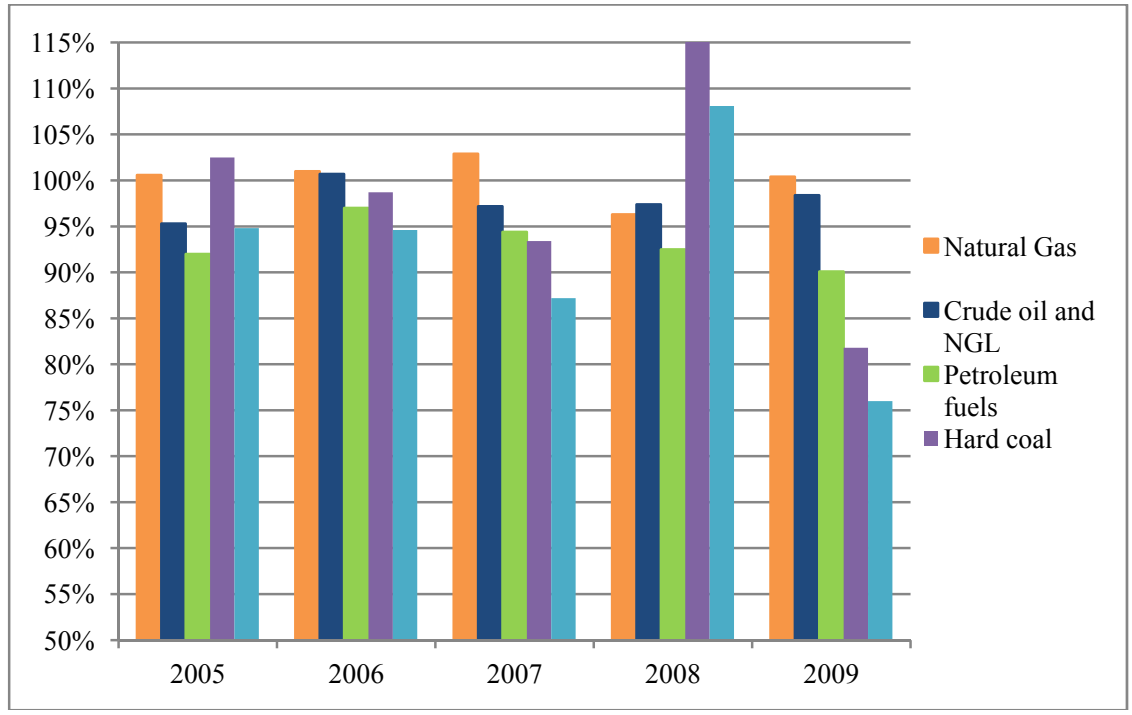

Figure 1: $\quad$ Primary energy resources import for the period 2005-2010 [3].

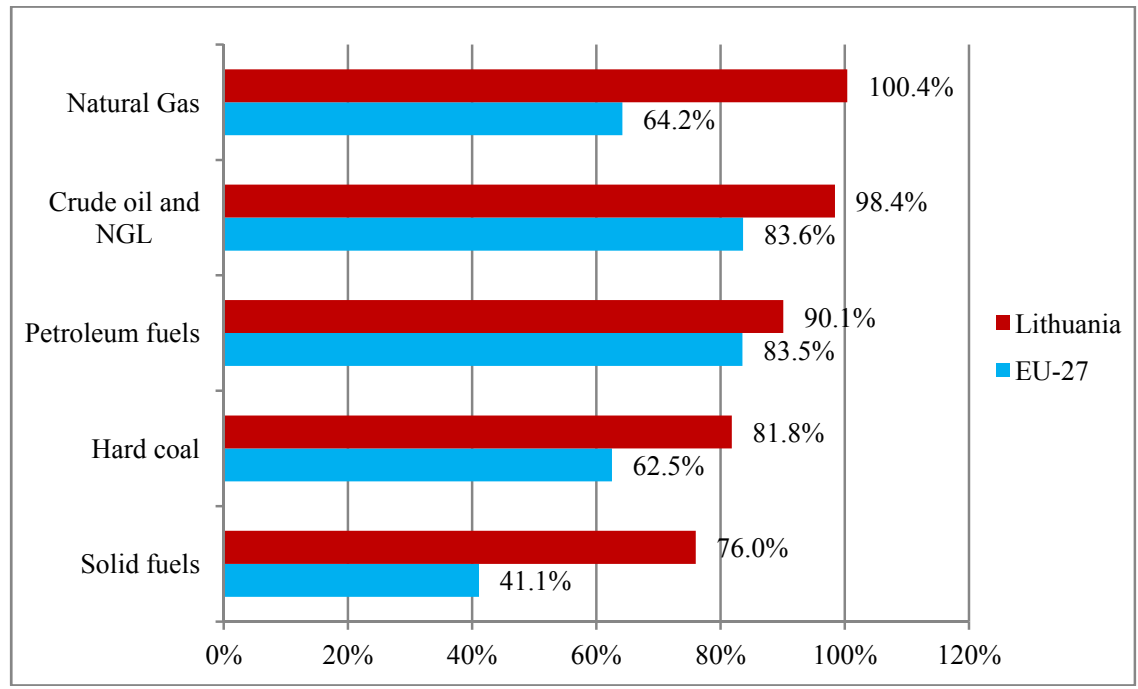

Figure 2: $\quad$ Import dependency in 2009 [3].

Lithuania is isolated from the EU energy systems: there are no electricity interconnections with Continental Europe and the country is dependent on a single external gas supplier. In addition, Lithuania imports more than a half of its electricity from neighbouring countries, with most of the remainder of electricity generated by using fossil fuels supplied by a single source. In fig. 3 we can see 
changes in electricity self-sufficiency before shut down of Ignalina NPP (Lithuania-2008) and after shut down of Ignalina NPP (Lithuania-2010) and compare results with other EU countries. We can notice that shut down of NPP significantly reduced electricity self-sufficiency despite the fact that Lithuanian electricity generating capacity exceeds the demand about three times.

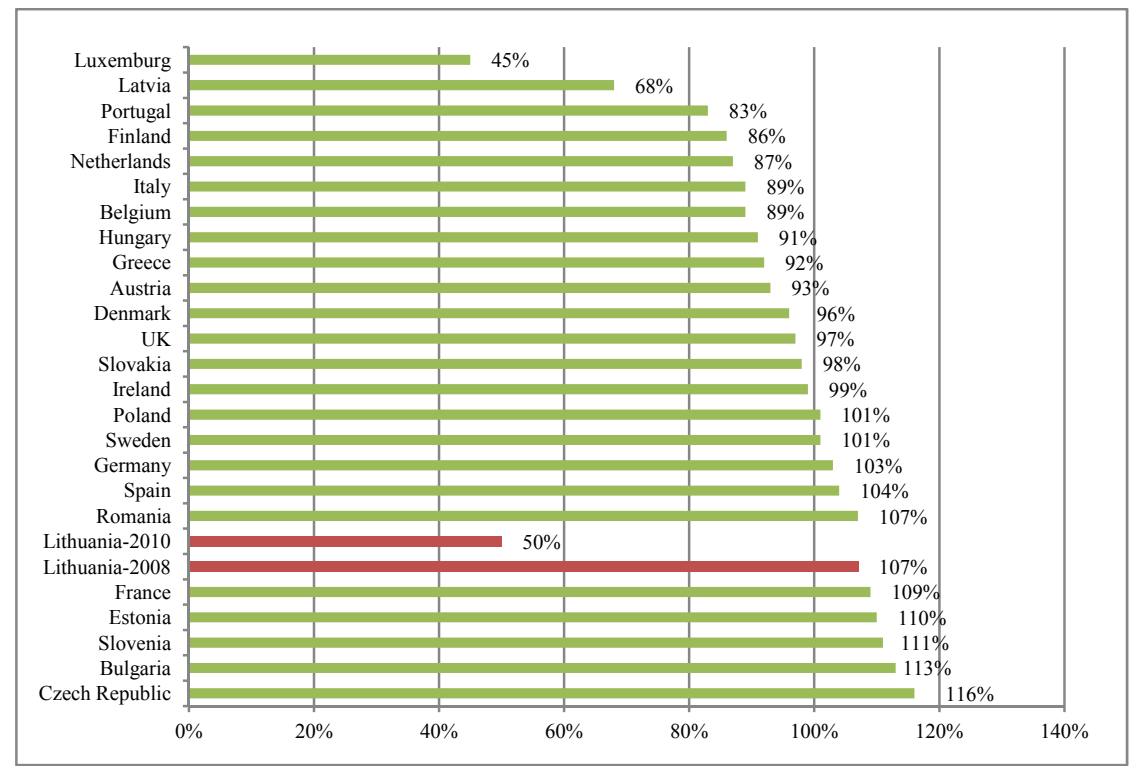

Figure 3: $\quad$ Electricity self-sufficiency of EU-27 [3].

\section{Energy security initiatives}

In the middle of 2011, the Government of the Republic of Lithuania endorsed the National Energy (Energy Independence) Strategy. The purpose of this document is to define the main objectives of the Lithuanian state in the energy sector, setting national targets for the implementation of strategic initiatives until 2020, and to lay down guidelines for the development of the energy sector until 2030 and 2050. The main goal of the Strategy is Lithuania's energy independence before year 2020. Energy independence will offer an opportunity to freely choose the type of the energy resources and the sources of their supply (including local production), which are in the best interests of the Lithuanian consumers and satisfy the needs for the energy security of the state. In fig. 5 a scheme is presented with the steps of reducing energy dependence on the single external energy supplier [5].

All initiatives are divided into seven groups: electricity, heating, gas, oil, renewable energy sources, energy efficiency and environment, and the reduction of $\mathrm{CO}_{2}$ emissions. In every group current situation is analysed and vision and strategic initiatives are proposed. The following new energy objects are 
mentioned as strategic initiatives: integration with European energy systems (Lithuanian-Poland and Lithuanian-Sweden power connections), new nuclear power plant, liquefied natural gas (LNG) terminal, gas pipeline between Lithuanian and Poland, and underground gas storage. Also liberalization of electricity, heat and gas markets is highlighted.

For comparison of particular energy object impact into energy security level four objects were selected: Lithuanian-Sweden power connection, LithuanianPoland power connection, new Visaginas nuclear power plant and liquefied natural gas terminal in Klaipeda.

The first strategic object which is under construction is Lithuanian-Swedish power connection (NordBalt). An electricity line with capacity of $700 \mathrm{MW}$ is planned to be built by the end of 2015. It will allow connecting to the Scandinavian electricity network, trading electricity with the Nordic countries, and accessing cheaper balancing reserves [5].

Another power connection is between Lithuania and Poland (LitPolLink). The cross-border power link between Lithuania and Poland is of primary importance to eliminate the isolation of Lithuania's electricity sector, connect to ECN and integrate into the European energy market. The LitPolLink will be built in 2 stages. In the first stage (in 2016), the link will have the capacity of $500 \mathrm{MW}$ and then reach the capacity of $1000 \mathrm{MW}$ by 2020 [5].

The main changes in gas sector are to build the liquefied natural gas (LNG) terminal in Klaipeda. The main desired functionalities of this terminal are the following: supply of natural gas will be diversified and the country will not be dependent on a single supplier of gas; emergency natural gas reserve function will be provided, thus Lithuania will be able to independently cover emergency demand for gas; the country will gain access to gas spot markets; preconditions for forming a primary gas market in Lithuania will be fulfilled [5].

The main strategic project in electricity generation until 2020 is the construction of the Visaginas NPP (VNPP) in the same place as that of Ignalina NPP. Although the investment is large, it is equal to around 10 years of payments for the imported gas to produce the same quantity of electricity. With regard to this, the Visaginas NPP is the most viable option to fill the electricity supply gap. It will additionally bring a number of benefits. At the same time, the issue of nuclear waste management will be handled already in the planning phase of the Visaginas NPP project. The NPP will operate for more than 50 years [5].

\section{Energy security assessment}

Two methods are used for security of energy supply assessment: energy security analysis and identification and assessment of energy security level. General energy system security assessment is schematically given in fig. 4. Energy security analysis is comprised of probabilistic [1] and economical [6] simulations of disturbed energy system. Probabilistic energy security investigation is directed towards assessment of various risks (technical, economic, sociopolitical) for stable energy supply under reasonable prices and analysis of risk evoked outcomes. Economic model is based on energy disturbances or disturbed energy 
system modelling. In this paper assessment of energy security level, which is based on formation and assessment of indicator system, is analysed more thoroughly.

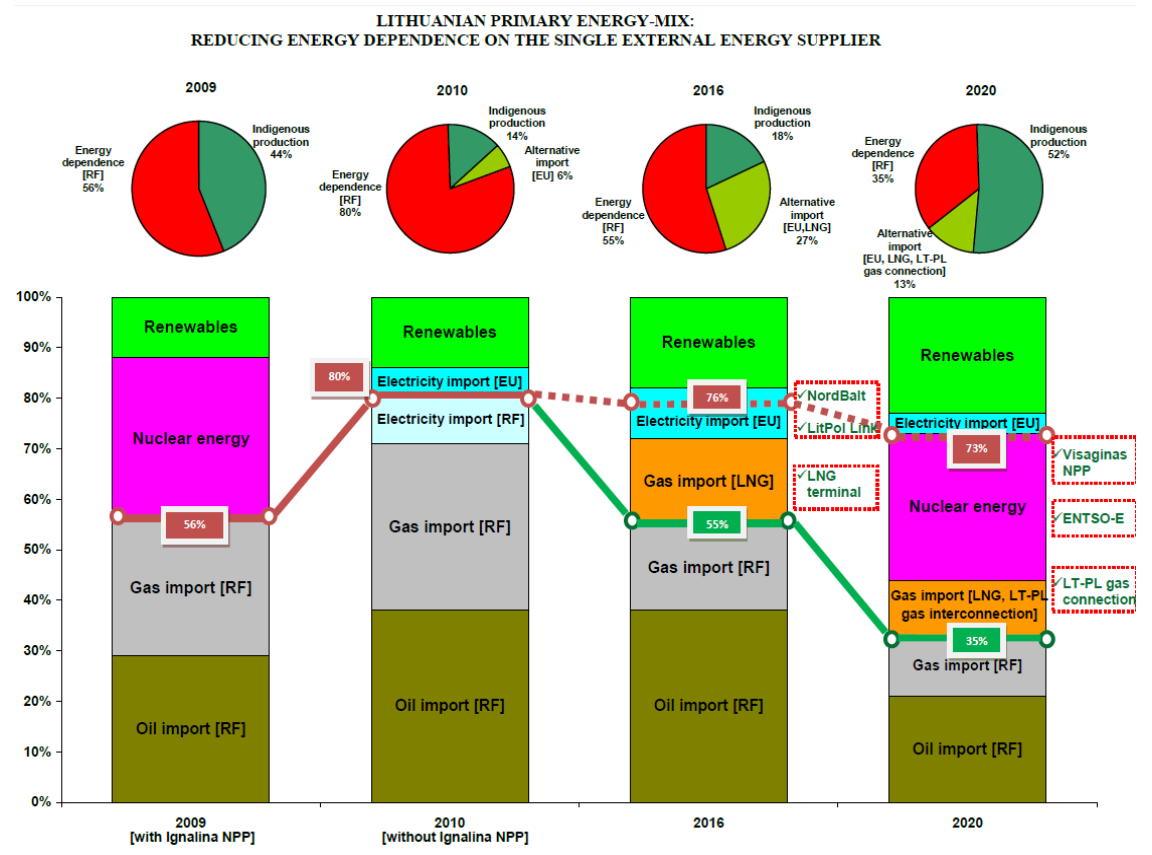

Figure 4: Reducing energy dependence steps on the single external energy supplier [5].

A system consisting of 68 energy security indicators was created for energy security assessment and comparison of new energy objects. Security indicator is a special index which gives numerical values to important issues for security of energy sector. The algorithm for security of energy supply assessment using security indicators proposed in this paper can be briefly outlined as follows: describing energy security indicators; grouping indicators to different blocks; estimating critical and non-critical values of security indicators; calculating normalized indicator values; assessing weights of indicators and blocks of indicators; performing sensitivity analysis of indicators in critical situations; calculating energy security level; presenting recommendations regarding security level support and improvement [4].

Six scenarios were analysed for the comparison of energy security level. The situations in 2007 and 2010 were presented as basic scenarios.

The year 2007 was chosen because during that year Ignalina NPP was still in operation. Year 2010 was the first year after the shutdown of Ignalina NPP. The remaining 4 scenarios described the situations, when comparing with the year 2010, Lithuanian energy system was supplemented with a new object: power 
connection between Lithuania and Sweden (NordBalt), liquefied natural gas (LNG) terminal, power connection between Lithuanian and Poland (LitPolLink), new power plant in Visaginas (VNPP).

Energy security level is estimated at the 15 point scale. This scale is divided into three main parts - normal mode (11-15 points), pre-critical mode (6-10 points) and critical mode (1-5 points). These three parts are divided into five equal parts respectively.

Each indicator value in investigated year is estimated by points from 1 to 15 at 15 point scale - this is the most minimal scale, which rather sensitively responds to indicator changes. The obtained comparable results are given in table 1, fig. 5. As can be seen, in 2007 energy security level was equal to 7.40 and it reduced by almost $6 \%$ in 2010, when Ignalina NPP was shut down. The introduction of new power objects improves energy security level from $5 \%$ to almost $13 \%$ if compared to 2010 .

Table 1: $\quad$ Energy security level in different scenarios.

\begin{tabular}{|c|c|c|c|c|c|c|}
\hline & 2007 & 2010 & NordBalt & LNG & LitPolLink & VNPP \\
\hline Energy security level & 7.40 & 6.60 & 7.44 & 8.36 & 7.38 & 8.48 \\
\hline
\end{tabular}

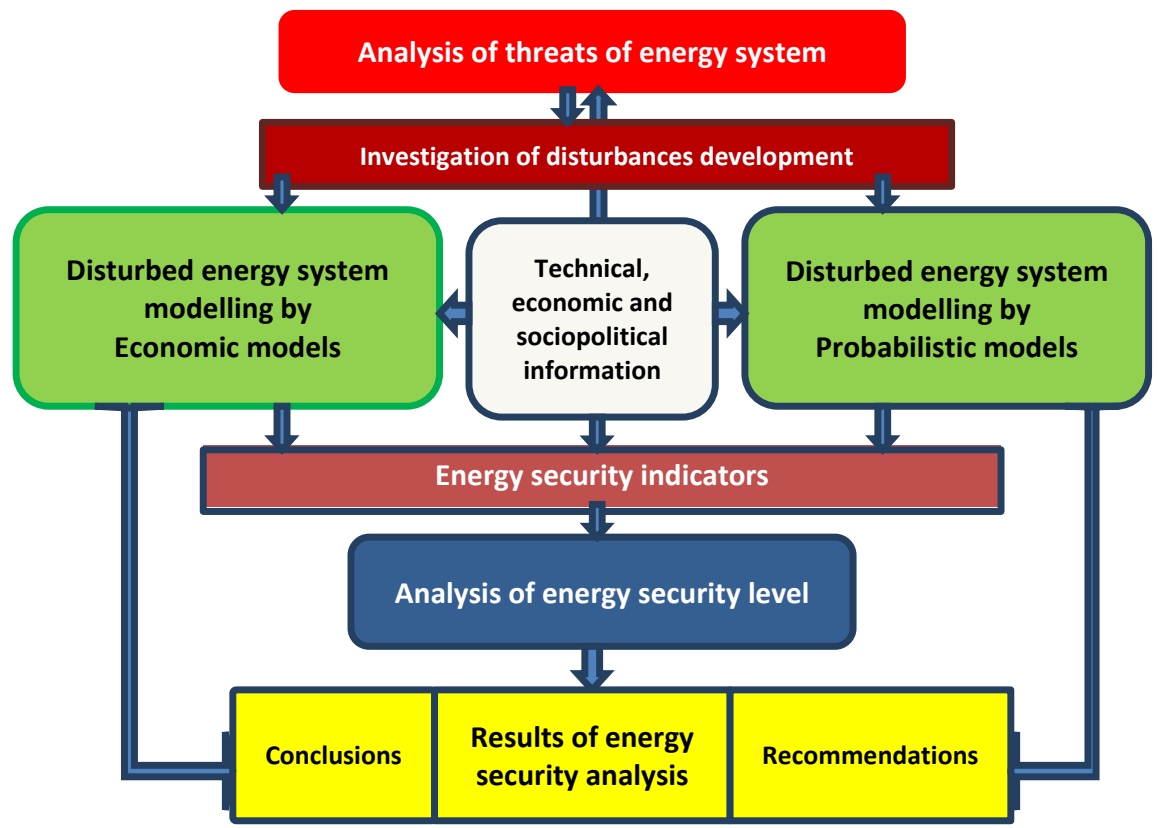

Figure 5: Scheme of methodology. 
If all main strategic projects of Lithuanian energy independence were implemented, the maximum energy security level would reach 12 points at the 15 point scale or $80 \%$ at the 100 point scale system (fig. 5). Realistically this index would be smaller due to interaction between the projects, however, this could be compensated with supplementary factors, foreseen in energy independence strategy.

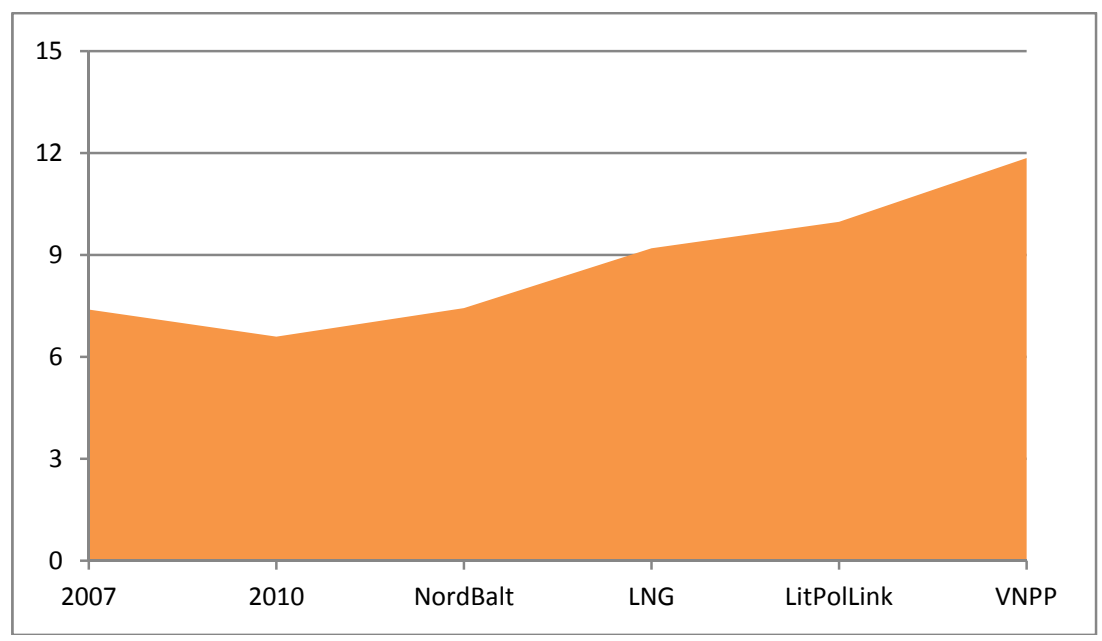

Figure 6: Common energy security level by year 2025.

\section{Conclusions}

The situation of Lithuania's dependences from original energy sources is presented in the article, meanwhile National Energy Independence Strategy approved by the Republic of Lithuanian Government is reviewed. Energy supply security evaluation methodology, which is designed to calculate various scenarios submitted in the National energy strategy, is presented in the paper as well.

Ignalina NPP shutdown had both negative (increase of electricity price, gas and electricity import) and positive (real electricity market emerged, Lithuanian electricity production dependence on one power plant unit disappeared, renewable energy sources expansion increased) outcomes on Lithuanian energy security.

Calculations revealed that Lithuanian energy security level after Ignalina NPP shutdown reduced slightly, approximately $6 \%$.

New Lithuanian energy development projects, such as electricity connections with Sweden and Poland, liquefied natural gas terminal, and new power plant all increase Lithuanian energy security level. In the work it was revealed that electricity connection with Sweden would increase energy security level by approximately $4.5 \%$, LNG terminal - by $11 \%$, whereas Visaginas NPP - by $12 \%$. 


\section{Acknowledgement}

This research was funded by a grant (No. ATE-06/2012) from the Research Council of Lithuania.

\section{References}

[1] Augutis, J., Matuzienė, V., Krikštolaitis, R., Pečiulytė, S. and Norvaiša, E. Analysis of security of energy supply assessment methods. Energetika (Power Engineering), 54(4), pp. 1-9, 2008.

[2] European Union. Access to European Union law. http://eur-lex.europa.eu/

[3] European Commission. Statistics and Market observatory. http://ec.europa.eu/ energy/observatory/index en.htm

[4] Augutis, J., Krikštolaitis, R., Pečiulytė, S. and Konstantinavičiūtè, I. Sustainable development and energy security level after Ignalina NPP shutdown. Technological and Economic Development of Economy, 17(1), pp. 5-21, 2011.

[5] National Energy (Energy Independence) Strategy. Government of the Republic of Lithuania endorsed the National Energy (Energy Independence) Strategy by Resolution No. 1426 on October 6, 2010.

[6] Martišauskas, L. OSEMOSYS model application for disturbed energy system modelling. 9th annual conference of young scientists on energy issues CYSENI 2012: international conference, Kaunas, Lithuania, 24-25 May, 2012. Kaunas: LEI, 2012. ISSN 1822-7554, p. 323-335. 